\title{
Slope Stability Analysis of “Vorobyovy Gory” Landslide in Moscow
}

\author{
Tao D. ${ }^{1,2}$, Barykina O.S. ${ }^{1}$, Kang K. ${ }^{1}$ \\ 1. Geological Faculty, Moscow State University, Moscow 119991, Russia \\ 2. Engineering Institute, China University of Geoscienses (Wuhan), Wuhan 430074, China \\ E-mail:1507674066@qq.com
}

\begin{abstract}
There are many engineering-geological problems in Moscow, including seepage deformation, karst and landslide. Among them, landslides develop along the Moscow River and its branches. This paper aims to analyze the slope stability of "Vorobyovy Gory" landslide with the help of the program GeoStudio. According to the limit equilibrium method, we can know the slope stability. In addition, we can know the internal friction angle among in the physical and mechanical parameters of soil layer has the greatest influences on its stability by sensitivity analysis. Finally, we can get the probability of damage by probabilistic analysis.
\end{abstract}

Keywords: Slope stability; Sensitivity analysis; Probabilistic analysis; Vorobyovy Gory; Moscow.

\section{Introduction}

Moscow city is located in the middle of the eastern European platform. From the surface down to a depth of $150 \mathrm{~m}$, it distributed as quaternary soil layer from top to bottom, sand and clay deposits of the cretaceous and Jurassic periods. Geological hazards in this area are mainly seepage deformation, karst and landslide [1]. Until the 19th century, the absolute height of Vorobyovy Gory was $117.5 \mathrm{~m}$ [2], and the maximum recorded flood caused the water level to rise 8.5 meters above the low water level, namely to 126 meters. Significant datum displacements happened in 1954, the largest of which was over $40 \mathrm{~mm} / \mathrm{month}$, people could see many cracks and fractures at 250-300 m downstream of the metro bridge, in the central part of Vorobyovy Gory, and the displacement rate was 10-15 cm/year [3]. Between 1955 and 1960, river levels rose at a rate of 2-2.5 meters per year, in the middle of Vorobyovy Gory, the coast receded by 2-3 $\mathrm{m}$ in five years. In 1956, the Moscow hydrogeological station concluded that there had been a number of landslides on Vorobyovy Gory, the longest of which was 100 meters long. In 1974, people could see the changes of datum plane on the back of steep, these deformations could as the failure of pedestrian stairs and asphalt pavement, the datum plane displacement during this period was between $0.030 \mathrm{~m}$ and $4.064 \mathrm{~m}$. However, the deformation according to the collection of geographic survey data from 1975 to 1983 changed greatly, moving about $54 \sim 66 \mathrm{~cm}$ [3] towards the river, indicating that a deeper landslide deformation took place here. In the mid-1990 s, the total displacement on the slope and on the embankment wall was 190 and $130 \mathrm{~mm}[4,5]$ respectively. In the $1990 \mathrm{~s}$, the maximum deformation occurred 150 meters downstream of the subway bridge, and the embankment wall pushed $113 \mathrm{~mm}$ into the river [6].In recent years, the deep landslide displacement activity under the subway, between the Subway Bridge and Khimfizika research institute manifested as the deformation of the river low dike. The development of the Moscow landslide in the riverbank and its many tributaries river valley, which poses a great threat to the related building facilities and the life safety of residents in the landslide area, the stability analysis of the sliding landslide can provide an effective basis for the prevention and control works.

Various uncertainties exist in slope engineering, such as inherent spatial variability of soil properties, changing environmental conditions. Effects of these uncertainties on probability of slope failure are often significant .People have developed several probabilistic methodologies to incorporate these uncertainties in slope stability analysis, such as the First Order Second Moment method, First Order Reliability Method, Monte Carlo Simulation method [7]. This study bases on Monte Carlo simulation with limit equilibrium method (Morgenstern-Price method). The analysis accounts for the statistical uncertainty due to limited data. In the study, the limited data is mainly about soil properties obtained from field sampling and laboratory tests. Prior to probabilistic analysis, sensitivity analysis aims to the main factors for slope stability.

In Russia, probabilistic analysis was conducted by some scholars [8, 9], however, which is yet not routine in practice of real construction. Based on previous field exploration data and published references, this paper makes a sensitivity analysis and probabilistic analysis of the physical and mechanical parameters of soil layer affecting the Vorobyovy Gory landslide by means of numerical simulation.

\section{Model building}


The landslide of Vorobyovy Gory is located on the right bank of the Moscow river .On the hill is the main building of the Moscow State University, while the opposite bank is the Luzhniki stadium, as shown in Fig.1. The underlying bedrock of the landslide is carboniferous limestone, and the landslide body has quaternary soil layer and cretaceous and Jurassic soil layer. In order to simplify the model, according to reference [10], 10 types of soil layer with different physical and mechanical parameters are set, with 1-9 as soil layer and 10 as rock layer, as shown in Fig. 2. The physical and mechanical parameters of different geotechnical elements show in table 1[11].

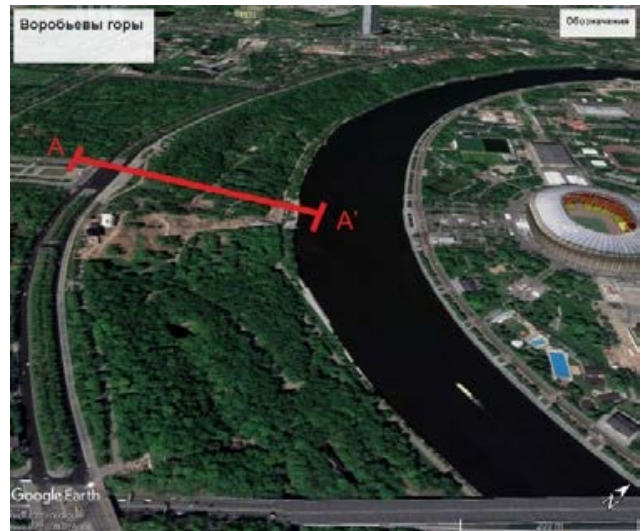

Fig 1. Area map of Vorobyovy Gory landslide (based on Google Earth), where AA 'is the calculated section

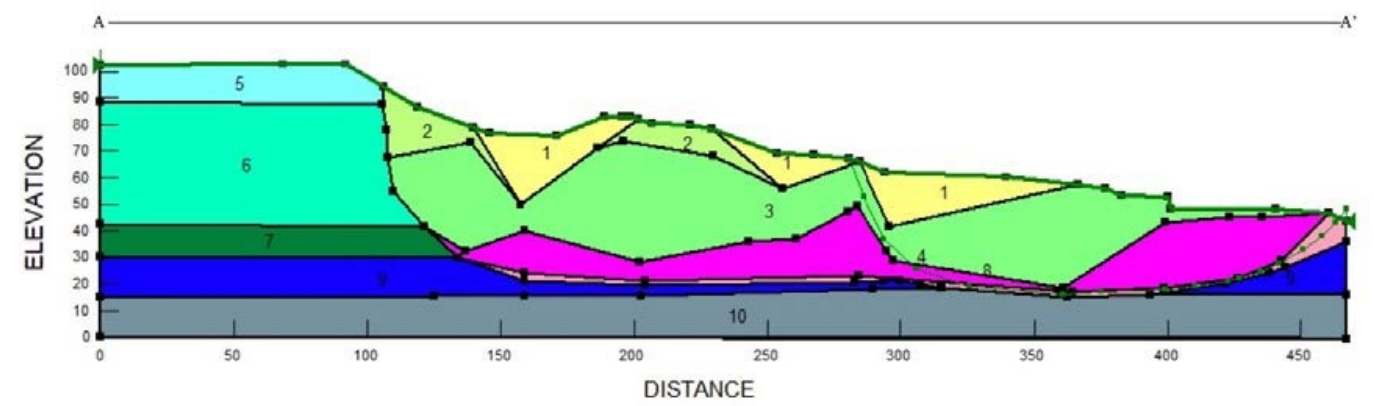

Fig 2. Calculation section of Vorobyovy Gory landslide

Table 1. Physical and mechanical parameters of soil layer element in landslide

\begin{tabular}{llll}
\hline No & Unit weight $\left(\mathrm{kN} / \mathrm{m}^{3}\right)$ & Cohesion $(\mathrm{kPa})$ & Friction angle $\left(^{\circ}\right)$ \\
\hline 1 & 20.6 & 4.0 & 16.0 \\
2 & 21.3 & 3.0 & 18.0 \\
3 & 19.3 & 0.6 & 22.0 \\
4 & 17.7 & 2.8 & 15.0 \\
5 & 21.5 & 3.3 & 19.0 \\
6 & 20.2 & 2.3 & 26.0 \\
7 & 19.3 & 6.5 & 17.0 \\
8 & 17.5 & 1.7 & 5.0 \\
9 & 17.8 & 10.8 & 13.0 \\
10 & 18.8 & 9.0 & 15.0 \\
\hline
\end{tabular}

\section{Slope stability calculation based on limit equilibrium method}

According to reference [11], we found that sliding surface of No.1 has damaged, and sliding surface of No.2 has tendency of damage. Therefore, taking stability analysis for No.1 and No.2 sliding surfaces is necessary. Limit equilibrium analysis method of slope stability assessment has been applied in the field of geotechnical engineering for decades [12]. In this study, we can calculate the stability of the Vorobyovy Gory slope by Morgenstern-Price method in limit equilibrium method [13].In this paper, the sliding surface of No.1 and No.2 are calculated. Interestingly, the results of calculation show that the Factor of Safety (FOS) of landslides under the condition of two sliding surfaces are FOS=0.979 and FOS=1.109 respectively, as shown in Fig 3 and Fig 4. The green part is the sliding body, and the white boundary is the sliding surface. The FOS is lower, the landside mass more unstable. When the FOS $<1.0$, it means that, the landside mass is unstable. In contrast, when the FOS $>1.0$, it means that, 
the landside mass is stable. Therefore, we can know that the sliding surface of No.1 is unstable, the sliding surface of No.2 is stable, which also accord with the actual investigation.

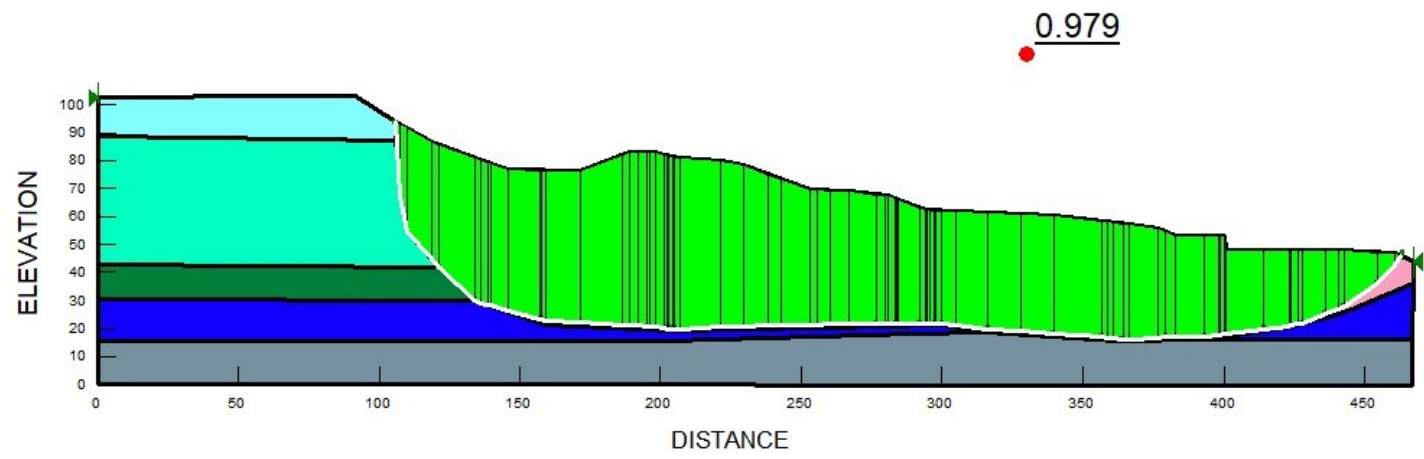

Fig 3. The FOS of No. 1 sliding surface calculated by limit equilibrium method

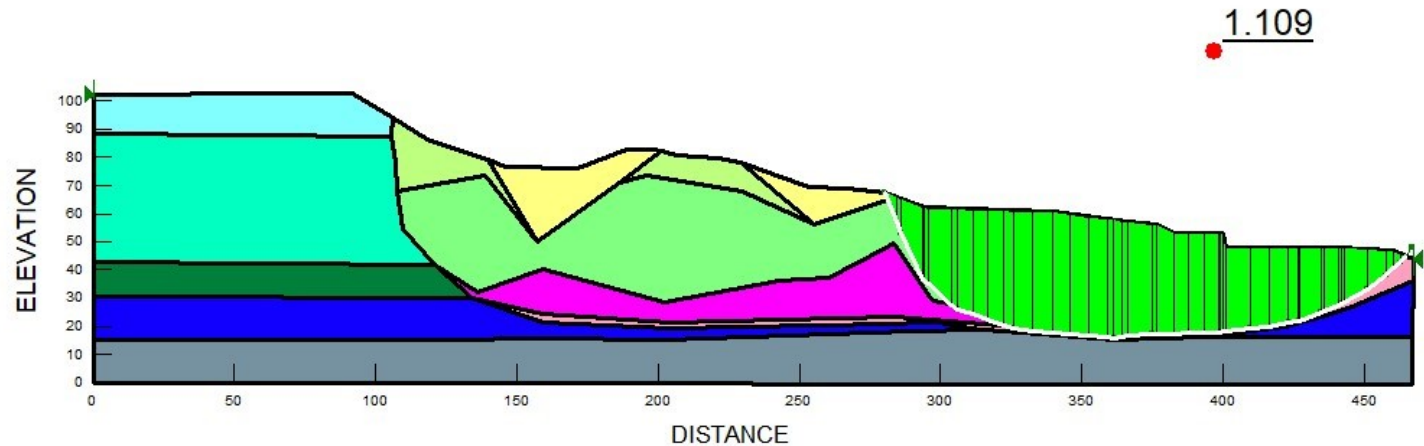

Fig 4. The FOS of No. 2 sliding surface calculated by limit equilibrium method

\section{Sensitivity analysis of landslide influencing factors}

Landslide sensitivity analysis mainly studies the correlation between various factors affecting landslide stability and the corresponding stability coefficient, which is measured by the ratio between the relative change rate of landslide stability coefficient and the relative change rate of each factor [14]. Based on the reference physical and mechanical parameters of large sliding surface soil layer in the damage surface, we can select one of the parameters, and increase the original value of $20 \%$ as the disturbance. For example, the soil layer of 3, unit weight $\gamma=24.00$ $36.00 \mathrm{kN} / \mathrm{m}^{3}$, cohesion $\mathrm{C}=2.24-3.36 \mathrm{kPa}$, internal friction angle $\Phi=4.00-6.00^{\circ}$. The sliding surface of No.1 just passes through mainly soil layer of 2, 3, 4, 8, so we only consider the parameters of 2, 3,4, 8- soil layer, and their variation range is shown in table 2 . In the results of sensitivity analysis, the abscissa represents the minimum value of the studied parameter with -1 , and the maximum value of the studied parameter with 1 , so as to compare the influence of different parameter changes on the safety coefficient. From the results, it is clearly that the higher the slope of the line represented by the parameters, the higher the sensitivity. The safety coefficient increases with the increase of the cohesion and the angle of internal friction, however the safety coefficient decreases with the increase of unit weight. As shown in Fig .5, the internal friction angle of 8-soil layer has the greatest influence on stability, followed by the unit weight of 2, 3, 4-soil layer. Similarly, we can increase the original value of $20 \%$ as the disturbance for the soil layer of 1 , therefore, the soil layer of 1 : unit weight $\gamma=16.48-24.72 \mathrm{kN} / \mathrm{m}^{3}$, cohesion $\mathrm{C}=3.20-4.80 \mathrm{kPa}$, internal friction angle $\Phi=12.8-19.2^{\circ}$. The sliding surface of No.2 passes through mainly 1,3 , 4, 8-soil layer, so we can only consider the parameters of 1, 3, 4, 8- soil layer, and the range of change is shown in table 3. As a whole, the change of internal friction angle of 8-soil layer has the largest influence on stability of No.2 sliding surface, followed by the change of unit weight of 1, 3, 4-soil layer, as shown in Fig .6.

Table 2. The variation range of physical and mechanical parameters of soil layer element in the sensitivity analysis of No. 1 sliding surface

\begin{tabular}{llll}
\hline No & Unit weight $\left(\mathrm{kN} / \mathrm{m}^{3}\right)$ & Cohesion $(\mathrm{kPa})$ & Friction angle $\left({ }^{\circ}\right)$ \\
\hline 2 & $17.04-25.56$ & $2.40-3.60$ & $14.40-21.60$ \\
3 & $24.00-36.00$ & $2.24-3.36$ & $4.00-6.00$ \\
4 & $14.16-21.24$ & $2.24-3.36$ & $12.00-18.00$ \\
8 & $14.00-21.00$ & $1.36-2.04$ & $1.36-2.04$ \\
\hline
\end{tabular}


Table 3. The variation range of physical and mechanical parameters soil layer element in the sensitivity analysis of No. 2 sliding surface

\begin{tabular}{llll}
\hline No & Unit weight $\left(\mathrm{kN} / \mathrm{m}^{3}\right)$ & Cohesion $(\mathrm{kPa})$ & Friction angle $\left(^{\circ}\right)$ \\
\hline 1 & $16.48-24.72$ & $3.20-4.80$ & $14.40-21.60$ \\
3 & $24.00-36.00$ & $2.24-3.36$ & $4.00-6.00$ \\
4 & $14.16-21.24$ & $2.24-3.36$ & $12.00-18.00$ \\
8 & $14.00-21.00$ & $1.36-2.04$ & $1.36-2.04$ \\
\hline
\end{tabular}

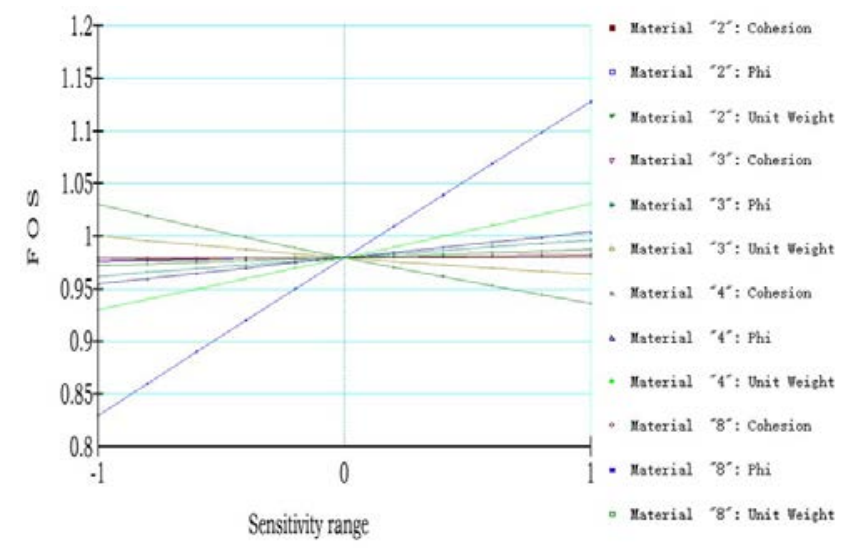

Fig 5. Sensitivity analysis curves of parameters of No. 1 sliding surface

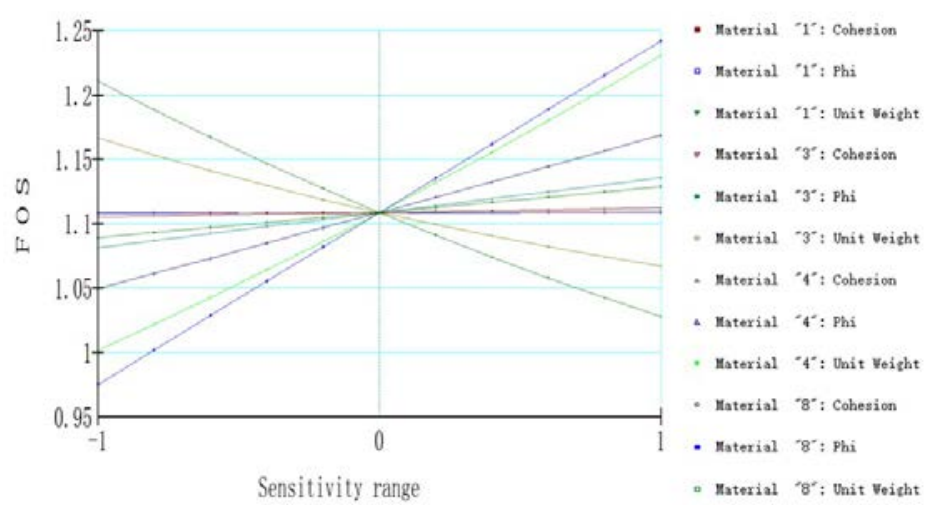

Fig 6. Sensitivity analysis curves of parameters of No 2 sliding surface

\section{Probabilistic analysis of landslide influencing factors}

The FOS is an index that reflects the relative stability of the slope. Due to the variability of the input parameters, the FOS cannot reflect the real risk level of the slope. In the probability analysis method, there is useful index that can quantitatively evaluate the stability or risk level of slope, which is failure probability. The probability of failure is the probability that the FOS is less than 1.0, which is the percentage of the number of tests in MonteCarlo with the FOS less than 1 and the total number of conversions. According to the Geostudio software, we got the failure probability of No.2 sliding surface, as shown in Fig .7. From the results, we can conclude that although the FOS of No.2 sliding surface $>1.0$, however, the instability probability of sliding surface of No.2 is $21 \%$, which means that sliding surface of No.2 may have the possibility of damage.

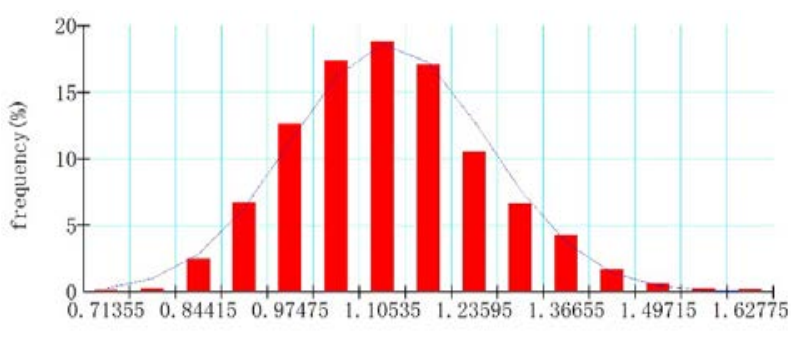

FOS

Fig 7. Probability density analysis curve of No 2 sliding surface 


\section{Conclusions}

1) The FOS of No. 1 sliding surface is less than 1.0, the FOS of No.2 sliding surface is greater than 1.0.

2) According to the sensitivity analysis, in the sliding surface of No.1, the internal friction angle of 8-soil layer has the greatest influence on stability, followed by the unit weight of 2, 3, 4-soil layer. In the sliding surface of No.2, the change of internal friction angle of 8-soil layer has the largest influence on stability, followed by the change of unit weight of 1, 3, 4-soil layer.

3) The failure probability of No.2 sliding surface is $21 \%$, which means that sliding surface of No.2 may have the possibility of damage.

4) This paper focuses on landslide of Vorobyovy Gory, which aims to help people know the situation of landslide of Vorobyovy Gory.

\section{References}

[1] Osipov V. Large-scale thematic geological mapping of Moscow area. In: Engineering Geology for Society and Territory (Volume 5). Springer, Cham; 2015. p. 11-16.

[2] Kotlov FV. Changes in the natural conditions of the territory of Moscow under the influence of human activity and their engineering and geological significance. Publishing House of the Academy of Sciences of the USSR; 1962.

[3] Paretskaya MN, Petrenko SI. Conclusion on the stability of the slope of the Lenin Mountains in the metro bridge. Engineering-geological Landslide Party; 1984.

[4] Koff GL, Petrenko SI, Likhacheva EA, Kotlov VF. Essays on geoecology and engineering geology of the Moscow metropolitan region. REFIA; 1997.

[5] Osipov VI, Medvedev OP. Moscow: geology and the city. Moscow Textbooks and Cartolithography Publishing House, Moscow; 1997. (In Russian).

[6] Paretskaya MN, Pigarina SD. Feedback on the "Concept of the possibility of using the facility on a landslide hazardous slope", 10/15/1998. (In Russian)

[7] Wang Y, Cao Z, Au SK. Efficient Monte Carlo simulation of parameter sensitivity in probabilistic slope stability analysis. Computers and Geotechnics. 2010;37(7):1015-1022.

[8] Fomenko IK, Pendin VV, Ionov VYu, Zuong MH. Slideslope danger forecast, based on the analisis of sensitivity of the stability coefficient to the pore pressure and seismic impact. Geology and Exploration. 2013(6):67-72. (In Russian).

[9] Zerkal OV, Fomenko IK. Influense of various factors on the results of probabilistic analysis of landslide activization. Engineering Geology. 2016(1):16-21. (In Russian)

[10] Kropotkin MP. Assessment of the landslide threat to the Vorobyovy Gory metro bridge in Moscow. Engineering Geology. 2016(3): 6-15. (In Russian)

[11] Kropotkin MP. Nature of large landslides in Moscow and the suburbs. Engineering geology. 2016(1):4-14. (In Russian)

[12] Krahn J. Stability modeling with SLOPE/W, An engineering methodology, 3rd Edition. Prepared and printed in-house by GEO-SLOPE International Ltd, Calgary, Alberta, Canada;2007.

[13] Morgenstern NR, Price VE. The Analysis of the stability of general slip surfaces. Geotechnique. 1965; 15(1):79-93.

[14] El-Ramly H, Morgenstern NR, Cruden DM. Probabilistic slope stability analysis for practice. Canadian Geotechnical Journal. 2002;39(3):665-683. 